\title{
Searching data for supporting archaeo-landscapes in Cyprus: an overview of aerial, satellite and cartographic datasets of the island
}

\author{
Athos Agapiou ${ }^{a}{ }^{*}$, Vasiliki Lysandrou ${ }^{a}$, Kyriacos Themistocleous ${ }^{a}$, Argyro Nisantzi ${ }^{a}$, Rosa \\ Lasaponara ${ }^{b}$, Nicola Masini ${ }^{c}$, Thomas Krauss ${ }^{d}$, Daniele Cerra ${ }^{d}$, Ursula Gessner ${ }^{d}$, Gunter Schreier ${ }^{d}$, \\ Diofantos Hadjimitsis ${ }^{a}$
}

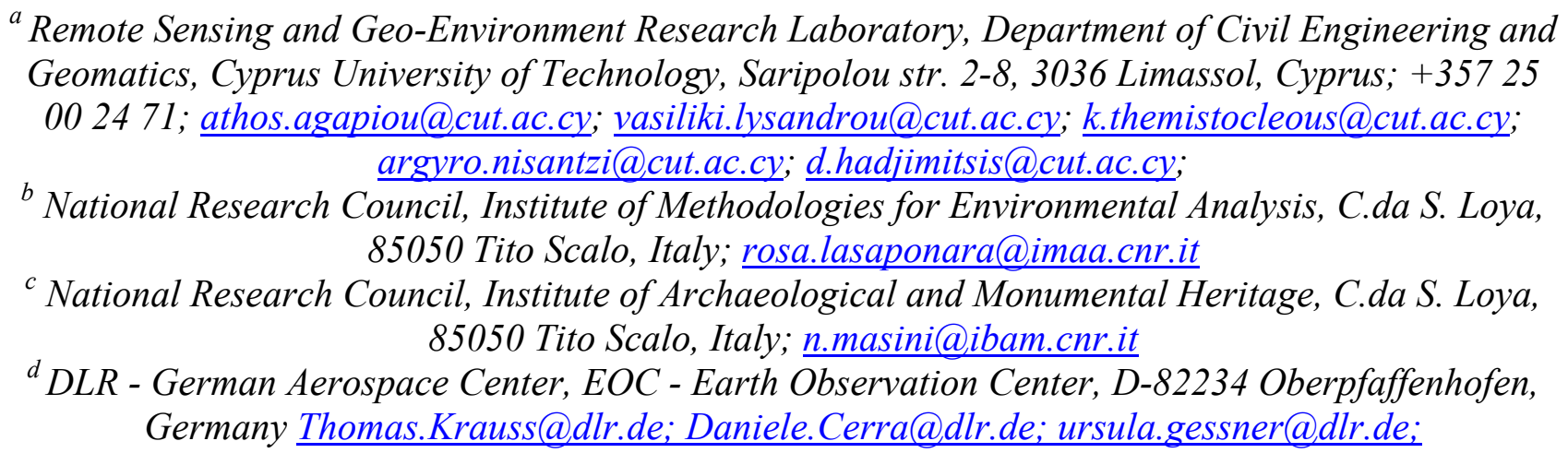
Gunter.Schreier@dlr.de

\begin{abstract}
The landscape of Cyprus is characterized by transformations that occurred during the 20th century, with many of such changes being still active today. Landscapes' changes are due to a variety of reasons including war conflicts, environmental conditions and modern development that have often caused the alteration or even the total loss of important information that could have assisted the archaeologists to comprehend the archaeo-landscape.

The present work aims to provide detailed information regarding the different existing datasets that can be used to support archaeologists in understanding the transformations that the landscape in Cyprus undergone, from a remote sensing perspective. Such datasets may help archaeologists to visualize a lost landscape and try to retrieve valuable information, while they support researchers for future investigations. As such they can further highlight in a predictive manner and consequently assess the impacts of landscape transformation -being of natural or anthropogenic cause- to cultural heritage.

Three main datasets are presented here: aerial images, satellite datasets including spy satellite datasets acquired during the Cold War, and cadastral maps. The variety of data is provided in a chronological order (e.g. year of acquisitions), while other important parameters such as the cost and the accuracy are also determined. Individual examples of archaeological sites in Cyprus are also provided for each dataset in order to underline both their importance and performance. Also some pre- and post-processing remote sensing methodologies are briefly described in order to enhance the final results. The paper within the framework of ATHENA project, dedicated to remote sensing archaeology/CH, aims to fill a significant gap in the recent literature of remote sensing archaeology of the island and to assist current and future archaeologists in their quest for remote sensing information to support their research.
\end{abstract}

Keywords: Remote Sensing Archaeology, Cyprus, Crop marks, Soil Marks, Archeolandscapes, ATHENA project

\section{INTRODUCTION}

The potential of geospatial data to access and analyse historical digital datasets for landscape and territorial analysis has been discussed in the past by several researches [1-3]. For instance, [2] has demonstrated how archive Digital Elevation Models (DEM) produced by aerial images can be exploited along with recent datasets from Airborne Laser Scanner (ALS) in order to generate automatic landscape changes through time. The study of landscape transformations is

Fourth International Conference on Remote Sensing and Geoinformation of the Environment (RSCy2016), edited by Kyriacos Themistocleous, Diofantos G. Hadjimitsis, Silas Michaelides, Giorgos Papadavid,

Proc. of SPIE Vol. 9688, 96881W - (C) 2016 SPIE · CCC code: 0277-786X/16/\$18 · doi: 10.1117/12.2241973 
increasingly relying upon sophisticated geo-services based on spatial information [4]. Inside the range of the current digital era accompanied by new kind of data sources and products, archaeologists seek to recover lost information of landscapes aiming at a better understanding and interpretation of archaeological findings. To do so, interpretation of archive aerial and satellite datasets is performed along with historical maps and recently acquired datasets. This procedure is usually undertaken into a Geographical Information System (GIS) which has the capability to visualize any other kind of new "big data" [5]. All these datasets can be inserted as time-stamped thematic layers into a GIS environment and then overlapped with other kind of geospatial information, also creating a basis for archaeological prediction models [6]. This procedure allows archaeologists to uncover the lost landscape, especially in regions that have been heavily transformed in recent years due to modern infrastructures including urban expansion and land use changes. As recent examples have shown for the area of Cyprus, urban expansion especially in the south cities of the island has be estimated to $300 \%$ for the period $1984-2010$ [7]. The benefits from passive and active satellite, aerial and close range remote sensing approaches, including archived and declassified satellite data, have been already acknowledged by several archaeological communities in Europe [8-13], Asia [14] and America [15] and great efforts have been carried out in the last years towards these directions. However, the accessibility to archive datasets is not an easy task for some regions. It should be noticed that archive information is usually found scattered and the information (metadata) associated with this data is also confused. Such examples are demonstrated within this paper, which aims to provide a basic catalogue and information related with remote sensing datasets for supporting archaeological research in Cyprus. Such information is still fragmental for many archaeologists and archaeological missions working in the island. Therefore, this paper points to fill this gap and at the same time to assist current and future archaeologists in their research using remote sensing datasets.

\section{CASE STUDY AREA}

The island of Cyprus is found in the eastern part of the Mediterranean Sea and it's the third largest island (Figure 1). It lies between latitudes $34^{\circ}$ and $36^{\circ} \mathrm{N}$, and longitudes $32^{\circ}$ and $35^{\circ} \mathrm{E}$. of the World Geodetic System (WGS). Troodos Mountains and Kyrenia Range are the two main mountainous regions of the island found in the central and northern part respectively. Between these two mountains is located the central plain of Mesaoria. The highest point on Cyprus is Mount Olympus at $1,952 \mathrm{~m}$ located in the center of Troodos range. The total size of the island is estimated to $9.251 \mathrm{~km}^{2}$ with more than $645 \mathrm{~km}$ of coastline. Cyprus is about $240 \mathrm{~km}$ long and $100 \mathrm{~km}$ wide. The earliest confirmed site of human activity on Cyprus is Aetokremnos, situated on the south coast, indicating that hunter-gatherers were active on the island from around 10,000 $\mathrm{BC}$. The multiple archaeological vestiges of the island comprise an undisputable testimony of its long history extending until the late medieval and ottoman eras. Still today, several archaeological missions both local and foreign are intensively investigating various sites revealing more aspects on the Cyprus long history.

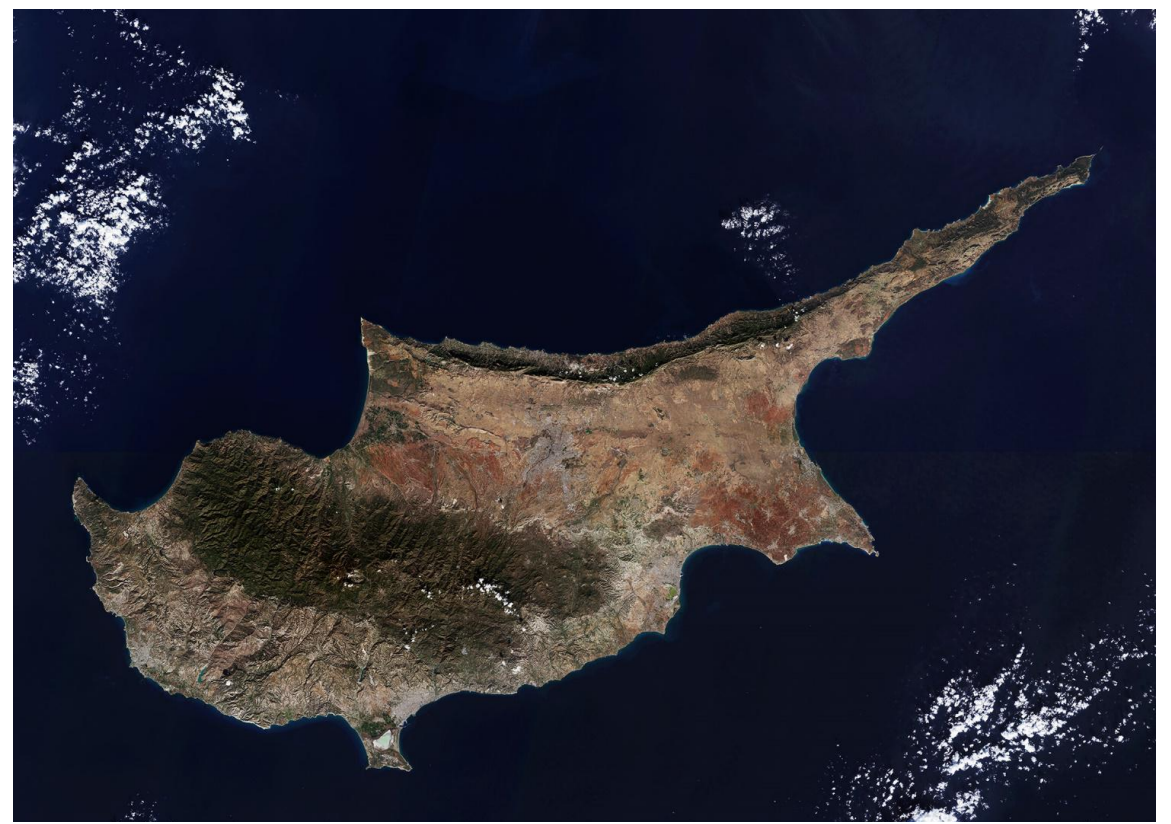

Figure 1: Cyprus island as captured from the Sentinel-2 sensor on the 11/03/2016 (Copernicus Sentinel data (2015)/ESAC) 


\section{LOCAL DATASETS}

\subsection{Archive maps}

The first cadastral maps of Cyprus are dating back to the late 19th century. During the period 1878 until 1882 Lord Kitchener created the first topographical map of the island, after he has just completed the survey of Western Palestine. The scale of the map is 1 inch to 1 mile, and several useful information can be found there. In addition to the topographical terrain, presented with its contours, also ruins, watermills and other important monuments are placed in the map. An example of the map over the archaeological sites of Nea Paphos and Tombs of the Kings can be seen in Figure 2 (left) [16]. This map is of great historic value for the archaeological surveys of Cyprus since it mapped for the first time "monuments" and "sites" of archaeological interest. The geolocation of this information however might be imprecise, and therefore archaeologists should be cautious when retrieving archaeological information out of this kind of datasets.

Since then several cadastral maps have been generated for Cyprus. These can be found in two different coordinate systems (i.e. Casini and LTM projections), depending on the period of the production of the maps, and in different scales according to the location. In general towns and village centers have larger scales, so further information and details can be tracked in those maps. Such maps are very useful for archaeologists working on the island for two reasons. On the one hand they can identify the sheet / plan and parcel number of their interest in order to use this combination for any formal request to the Department of Antiquities and to the Department of Land and Surveyors, and on the other hand they can still find hidden information in these maps such as Ancient Monuments (A.M) (see Figure 2, right). All these maps can be found in the Department of Land and Surveyors. The latest year of modification of these maps is mentioned in the lower part of the map providing in this way a terminus ante quem.
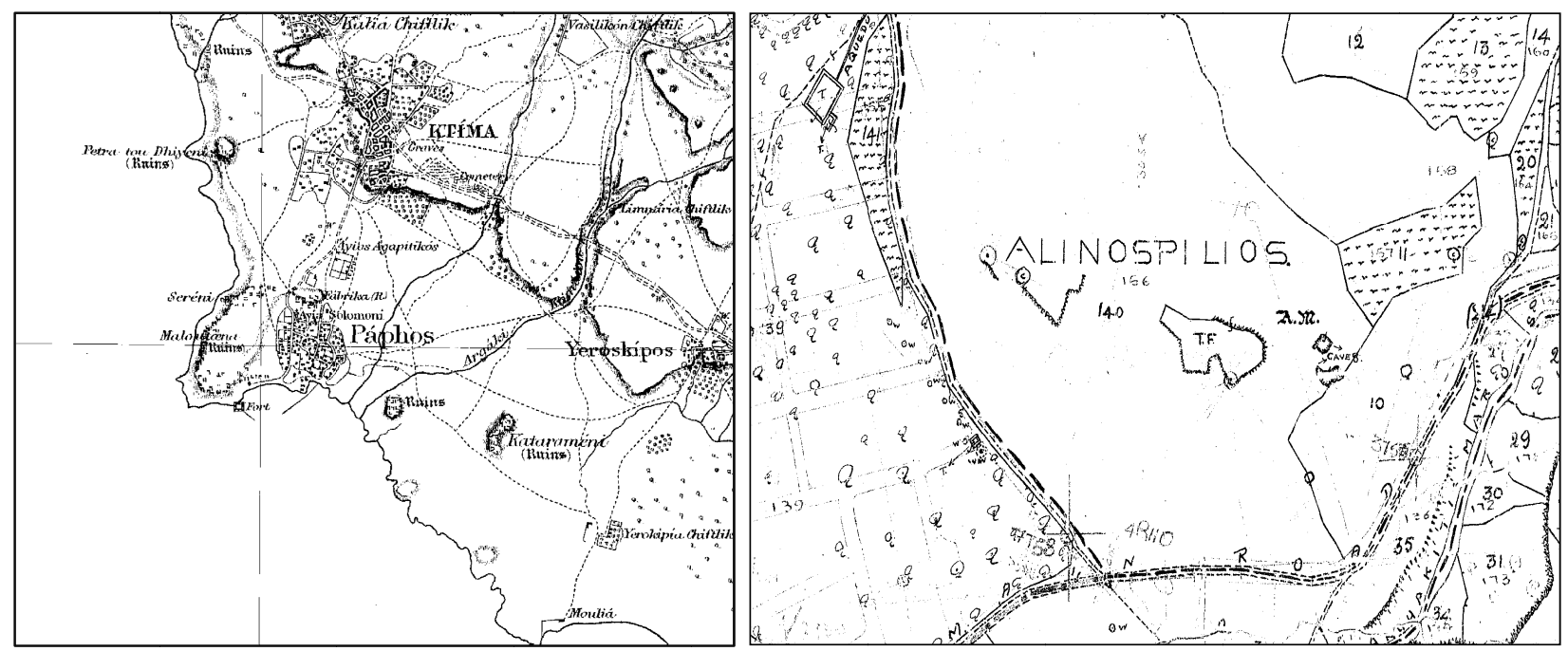

Figure 2: Kitchener's map over the archaeological sites of Nea Paphos and Tombs of the Kings (left) and cadastral map from the area of Anavargos village (locality Alinospilios also known as Ellinospilios and Ellinospilioi) indicating some Ancient Monuments (A.M), more specifically a partially preserved Hellenistic-Roman necropolis (right) (from Department of Land and Surveyors of Cyprus (C)

\subsection{Archive aerial images}

In Cyprus, compared to other areas of Europe, only one systematic mapping using aerial photographs has been carried out in the whole island. This was completed in 1963, just after the independence of Cyprus in 1960. The greyscale images were taken in stereo-pairs so 3D models of the topography of that period can be generated using standard photogrammetric procedures. These images can be also found as orthophotos (i.e. images corrected from elevation distortions etc.). The aerial images archive of Cyprus is of invaluable importance for archaeological investigations on the island, since it comprises images that have captured the island's icon prior to any modern development, such as the constructions of dams and roads, the urban expansion and other infrastructural work of natural changes. However, it 
should be noticed that these images exhibit a low Signal-to-Noise Ratio (SNR), which hinders the interpretation of the data. Post-processing is sometimes necessary in order to enhance and improve the quality of the images.

The next systematic airborne campaign was only taken in 1993, but it was restricted to the southern part of the island. The acquired images were once again panchromatic and stereo. True colour images (RGB) of the southern part of Cyprus have been acquired only in 2008 and 2014. The latest aerial survey was of high quality in terms of spatial resolution ( $25 \mathrm{~cm}$ ground sampling distance) indicating how technological improvements (i.e. oblique images) have changed the traditional aerial surveys. These images are useful in order to detect, map and visualize transformations of Cyprus' landscape. Indeed, in specific areas of the island such as the area of Paphos [7], the land use changes that occurred during the last decades were dramatic (300\% urban expansion) and rapid. Automatic change detection techniques could be applied so as to automatically or semi-automatically map these land use changes, but can be restricted due to the spectral resolution of the datasets (panchromatic and RGB images). Therefore, the manual digitization persists as the most common way to map the land use and land cover changes.

Archaeologists can purchase archive aerial images from the Department of Land and Surveyors, in order to map the changes over the landscape through the period from 1963 until 2014 (for the southern part of the island only). An example of the orthophotos taken in 2008 and 2014 over the archaeological site of Nea Paphos is presented in Figure 3 (e and $\mathrm{f}$ respectively). It is important to note that all these datasets exhibit a high spatial resolution (meter or sub-meter ground sampling distance). However, since the aerial images were taken mainly for the needs of the Department of Land and Surveyors, this resolution might be still insufficient to support micro-scale archaeological surveys (i.e. archaeological excavation), but is considered more appropriate for landscape scale studies.


Figure 3: Aerial images taken over the archaeological site of Nea Paphos: (a) aerial image of Cyprus before the Second World War (b) aerial image of 1945 taken from RAF; (c) aerial image taken in 1962; (d) aerial image of 1993; (e) aerial orthophoto of 2008 and (f) aerial orthophoto of 2014

Infrequently, further aerial images of Cyprus from different periods can be found, as for instance the aerial images of Royal Air Force (RAF) that captured some sites of the island during the 40's. Occasionally, these images are of high quality and several crop and soil marks can be spotted as seen in Figure 3b. However, in other aerial images, 
interpretation can be problematic due to the noise of the datasets. It has been demonstrated in [17] that such datasets might be fused together using pan-sharpening techniques in order to retrieve the lost archaeological marks and therefore assist archaeologists for better understanding a site. Other aerial images taken during the 70's are also available from the Department of Land and Surveyors.

Special attention should be given to the oldest aerial archive datasets - up to our knowledge- that cover the whole island of Cyprus. The images were taken before (or during?) the second World Word and now are catalogued in the Istituto Geografico Militare of Italy. These images are shown in a scale of 1:25000 and their original printed size is $698 \times 606$ $\mathrm{mm}$. A single image is usually a mosaic of three or more other aerial images and all these are stacked and joined together to complete an area. Although the quality of these images is not sufficient for micro-surveys, their historical value is of great importance since they are taken prior to any modern evolution of the island and therefore significant changes of the landscape can be observed. An example is shown in Figure 3a where the modern city of Paphos consisted in only two small villages, those of Ktima and Paphos. A further observation in landscape level comprises in the viewing the main rivers of Cyprus once flowing into the sea, a lost 'picture' of modern landscape due to the construction of dams (Cyprus has a total of 108 dams and reservoirs).

\section{OTHER DATASETS}

\subsection{Satellite images}

A variety of satellite multi-temporal datasets is currently available to researchers. Conversely, the majority of the high resolution satellite images were only acquired after 1999, when the first commercial satellite sensor with these characteristics (IKONOS) was launched. Since then, other multispectral sensors have been sent into space including QuickBird, GeoEye, WorldView, Pleiades etc. Satellite images dating before 1999 that can be used to support archaeolandscape studies are Landsat and SPOT 4. The spectral range of these images include the RGB and near infrared / middle infrared parts of the spectrum. It should be noticed that Landsat images are freely distributed from USGS: however, the spatial resolution of Landsat / SPOT 4 images is approximately one order of magnitude worse than the previously described satellites, and therefore might not fully support landscape studies. An example of these images is shown in Figure 4. 


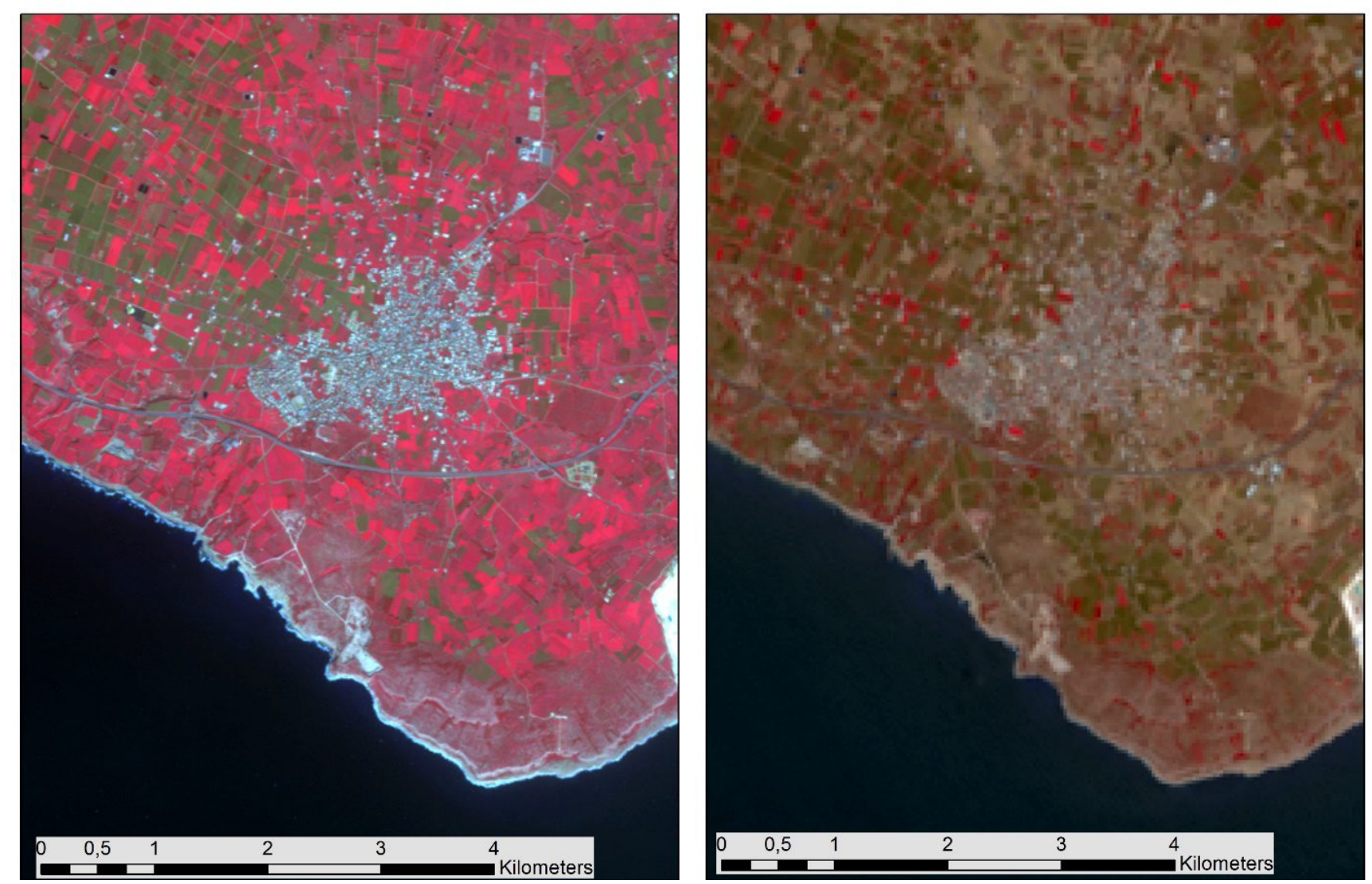

Figure 4: SPOT (left) and Landsat 8 DCM (right) of the western part of Cyprus. The images are shown as NIR-R-G false colour composites.

Sentinel-2 sensor, which started the distribution of satellite data only recently (December 2015) seems to be ideal for the detection of crop marks such as tells. As previous study has demonstrated [18] using simulated data, the spectral range $700 \mathrm{~nm}-800 \mathrm{~nm}$ (see Figure 1) can be of benefit in detection of Neolithic tells in central Greece. These images are freely distributed from the European Space Agency [19]. However, the spatial resolution of the images (20 meters' pixel size) results insufficient for the detection of smaller archaeological sites.

Spy satellite datasets from CORONA space program are another important source of information. During the operational phase of CORONA between 1960 and 1972, over 800,000 high-resolution images have been acquired. The oldest archive from CORONA images dates back to 1962, a year earlier to the first systematic aerial photography of Cyprus. CORONA images have been used in other areas in order to support archaeological research [20]. Some first studies from the potential use of CORONA images for archaeological research in Cyprus can be found in [17] although it should be mentioned that the quality of the images over Cyprus is relative poor (low SNR) compare to other areas of the world. CORONA were acquired at different spatial resolution, acquisition modes such as stereo etc. depending on the military interest for the area.

\subsection{Digital Globes - Inspire Directive}

Information related to the observation of landscape can be retrieved from 3D digital globes such as Google Earth $\odot$, Bing Maps $\odot$, NASA World Wind $\odot$ etc. These visualizations might be very useful for archaeologists as a starting point of their research since they can provide a synoptic view and also historical records of datasets. An example of the use of these tools is demonstrated in Figure 5, where historical images from Google Earth over the archaeological site of Palaepaphos (Old Paphos) are presented. As seen, new constructions in the western part of the modern village have changed the landscape of the area. It should be mentioned that these images are compressed and therefore possibly spatially down sampled, while their spectral resolution is also limited to the RGB bands. Moreover, the geolocation of the images might vary since these cannot be considered as geometrically corrected images. 

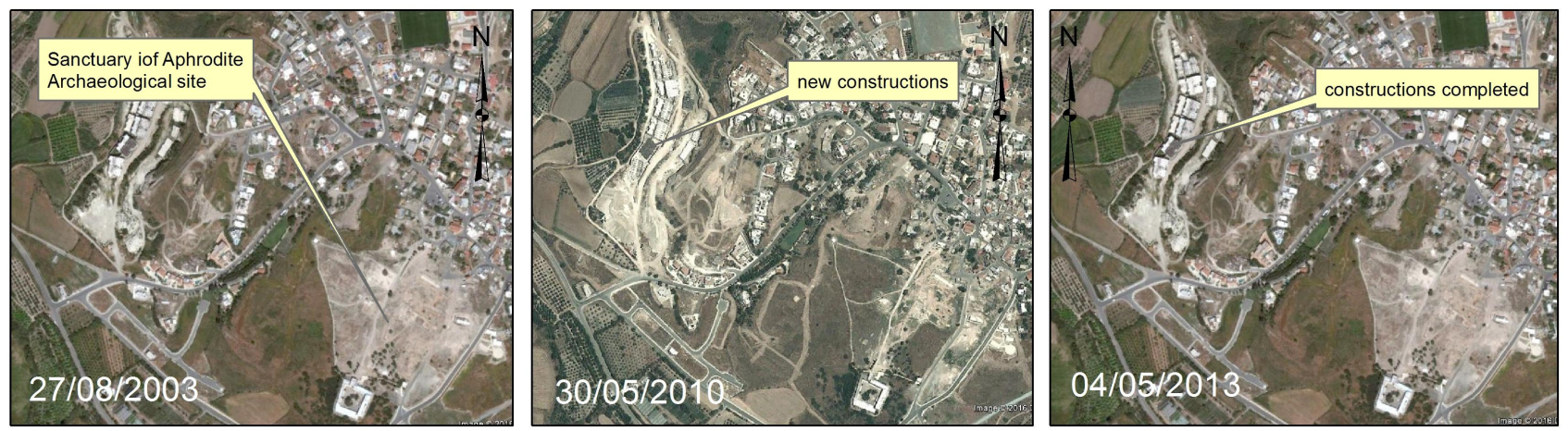

Figure 5: Google Earth images over the archaeological site of Palaepaphos. Three different snapshots from the 3D engine indicate the different phases of modern construction in the area (images from Google Earth (C)).

Recently ( $15^{\text {th }}$ of January 2016) the Department of Land and Surveyor of Cyprus has launched the Inspire geoportal [21]. The geocatalog (Figure 6), is freely accessible providing some important vector datasets from a variety of governmental authorities of Cyprus to the end users. According to [22], "this new e-service can be searched based on the metadata that have been prepared, they can be viewed, they can be downloaded and most importantly, they can be directly accessed by any GIS system or any other relevant application, and can be inter-related with other existing geospatial datasets of the users". These data follow the standards of the Inspire Directive (Directive 2007/2/EC). 



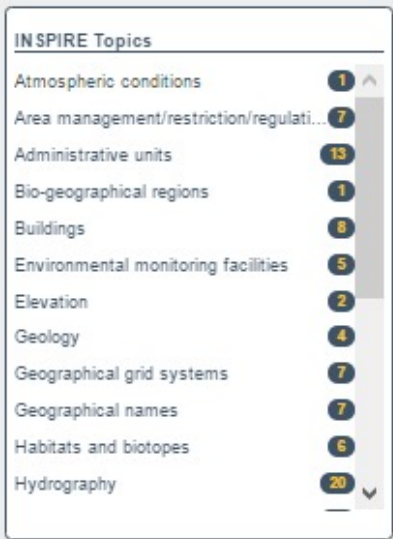

ISO-19139 Topics



Figure 6: Cyprus Inspire Geoportal [21]

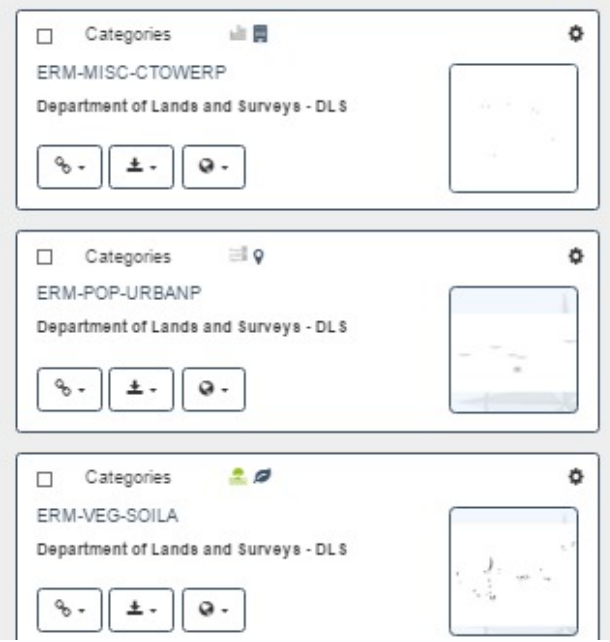

[21]

\section{DISCUSSION}

Archive information in terms of aerial images, satellite products and cadastral maps are undoubtedly useful for archaeologists in order to track significant changes occurred in landscape level and therefore better understand, interpret and rationalize their findings in a field scale. This paper presented a synoptic catalogue of some of the most important datasets that can be used for the island of Cyprus, their strength and weak aspects, their search source etc. Aim of the paper is to elucidate archaeological community operating in Cyprus for a resource information usually left aside from their research mainly due to lack of knowledge on what can be requested, from where, how can be used and what is more suitable for each case study. Additionally, this effort aims to give an impetus to the archaeologists to integrate such information sources into their research, as well as to give them an orientation on where to search for such data. 


\section{ACKNOWLEDGEMENTS}

The present communication is under the "ATHENA" project H2020-TWINN2015 of European Commission. This project has received funding from the European Union's Horizon 2020 research and innovation programme under grant agreement No 691936. Thanks are given to the Remote Sensing and Geo-Environment Laboratory of the Department of Civil Engineering \& Geomatics at the Cyprus University of Technology for its continuous support (http://www.cut.ac.cy).

\section{REFERENCES}

[1] Brumana, R., Oreni, D., Cuca, B., Rampini, A., Pepe, M., Open access to historical information for landscape analysis in an SDI framework, (2013) International Journal of Agricultural and Environmental Information Systems, 4 (3), pp. 18-40.

[2] Risbøl, O., Briese, C., Doneus, M., Nesbakken, A., Monitoring cultural heritage by comparing DEMs derived from historical aerial photographs and airborne laser scanning, (2015) Journal of Cultural Heritage, 16 (2), pp. 202-209.

[3] Gomez, C., Hayakawa, Y., Obanawa, H., A study of Japanese landscapes using structure from motion derived DSMs and DEMs based on historical aerial photographs: New opportunities for vegetation monitoring and diachronic geomorphology, (2015) Geomorphology, 242, pp. 11-20

[4] Cuca, B., Brumana, R., Oreni, D., Geo-portals: More sustainable governance of territory within spatial data framework, (2013) Proceedings of SPIE - The International Society for Optical Engineering, 8795, art. no. 87950G.

[5] Dell'Unto, N., Landeschi, G., Leander Touati, A.-M., Dellepiane, M., Callieri, M., Ferdani, D., Experiencing Ancient Buildings from a 3D GIS Perspective: a Case Drawn from the Swedish Pompeii Project, (2016) Journal of Archaeological Method and Theory, 23 (1), pp. 73-94.

[6] Danese M., Masini N., Biscione M., Lasaponara R. 2014. Predictive modeling for preventive Archaeology: Overview and case study. Central European Journal of Geosciences. March 2014,Volume 6, Issue 1, $42-55$

[7] Agapiou A., Alexakis D.D., Lysandrou V., Sarris A., Cuca B., Themistocleous K., Hadjimitsis D.G., 2015, Impact of Urban Sprawl to archaeological research: the case study of Paphos area in Cyprus, Journal of Cultural Heritage, 16(5), 671-680, http://dx.doi.org/10.1016/j.culher.2014.12.006

[8] Simon J. Keay, Sarah H. Parcak, Kristian D. Strutt, High resolution space and ground-based remote sensing and implications for landscape archaeology: the case from Portus, Italy, Journal of Archaeological Science, Volume 52, December 2014, Pages 277-292, ISSN 0305-4403, http://dx.doi.org/10.1016/j.jas.2014.08.010.

[9] Marco J. Giardino, A history of NASA remote sensing contributions to archaeology, Journal of Archaeological Science, Volume 38, Issue 9, September 2011, Pages 2003-2009, ISSN 0305-4403, http://dx.doi.org/10.1016/j.jas.2010.09.017.

[10] Stichelbaut, B., Gheyle, W., Saey, T., Van Eetvelde, V., Van Meirvenne, M., Note, N., Van den Berghe, H., Bourgeois, J. 2016. The First World War from above and below. Historical aerial photographs and mine craters in the Ypres Salient. Applied Geography, 66, 64-72, ISSN 0143-6228, http://dx.doi.org/10.1016/j.apgeog.2015.11.020.

[11] Lasaponara R., Leucci G., Masini N., Persico R., Scardozzi G. (2016) Towards an operative use of remote sensing for exploring the past using satellite data: The case study of Hierapolis (Turkey). Remote Sensing of Environment 174, $148-164$

[12] Goossens, R., De Wulf, A., Bourgeois, J., Gheyle, W., Willems, T. 2006. Satellite imagery and archaeology: the example of CORONA in the Altai Mountains. Journal of Archaeological Science 33(6): 745-755

[13] Agapiou A., Lysandrou V., 2015. Remote sensing archaeology: Tracking and mapping evolution in European scientific literature from 1999 to 2015, Journal of Archaeological Science: Reports, Volume 4, December 2015, Pages 192-200, ISSN 2352-409X, http://dx.doi.org/10.1016/j.jasrep.2015.09.010.

[14] Evans D H, Fletcher R J., Pottier C., Chevance J. B., Soutif D. et al. Uncovering archaeological landscapes at Angkor using lidar. PNAS, 12595-12600, doi: 10.1073/pnas.1306539110

[15] Chase A. F., Chase D. Z., Fisher C. T., Leisz S. J., Weishamper J. F., Geospatial revolution and remote sensing LiDAR in Mesoamerican archaeology. PNAS, vol. 109 no. 32,12916-12921, doi: 10.1073/pnas.1205198109

[16] Lysandrou V, Agapiou A., Hadjimitsis D. G., 2015. Impact of modern evolution of Paphos town to its ancient necropoleis: a multi-temporal GIS and earth observation analysis, Proc. SPIE 9535, Third International Conference on Remote Sensing and Geoinformation of the Environment (RSCy2015), 95350Y (June 19, 2015).

doi:10.1117/12.2192514 
[17] Agapiou A., Alexakis D. D., Sarris A., Hadjimitsis D. G., 2016, Colour to grayscale pixels: Re-seeing grayscale archived aerial photographs and declassified satellite CORONA images based on image fusion techniques, Archaeological Prospection (accepted).

[18] Agapiou A., Alexakis D. D., Sarris A., Hadjimitsis D. G., 2014. Evaluating the potentials of Sentinel-2 for archaeological perspective, Remote Sensing, 6(3), 2176-2194.

[19] Sentinel-2 catalogue, https://sentinel.esa.int/web/sentinel/missions/sentinel-2/data-products

[20] Hritz C. 2013. A malarial-ridden swamp: using Google, Earth Pro and Corona to access the southern Balikh valley, Syria. Journal of Archaeological Science 40(4): 1975-1987

[21] Geocatalog Inspire Cyprus, http://inspire.cyprus.moi.gov.cy

[22] Department of Land and Surveyors of Cyprus,

http://www.moi.gov.cy/moi/DLS/dls.nsf/All/3AFADA608098680DC2257F50003E627D?OpenDocument 